\title{
Comparative Efficacy of Insecticides on Bactrocera tryoni and Zeugodacus cucumis (Diptera: Tephritidae) in Laboratory and Semifield Trials in Fruiting Vegetables
}

\author{
L. J. Senior, ${ }^{1,2}$ B. P. Missenden, ${ }^{1}$ and C. Wright ${ }^{3}$ \\ 'Department of Agriculture and Fisheries, Ecosciences Precinct, Dutton Park, OLD 4102, Australia (lara.se- \\ nior@daf.qld.gov.au; brendan.missenden@daf.qld.gov.au), ${ }^{2}$ Corresponding author, e-mail: lara.senior@daf.qld.gov.au, and \\ ${ }^{3}$ Department of Agriculture and Fisheries, 28 Peters Street, Mareeba, QLD 4880, Australia (carole.wright@daf.qld.gov.au),
}

Subject Editor: Anthony Clarke

Received 24 January 2017; Editorial decision 19 March 2017

\begin{abstract}
In-field management of Bactrocera tryoni (Froggatt) and Zeugodacus cucumis (French) (Diptera: Tephritidae) in fruiting vegetable crops has relied almost exclusively on organophosphate cover sprays. Laboratory and semifield trials were performed to compare a number of alternative insecticides for efficacy against these species. A novel semifield method was used whereby the insecticides were applied to crops as cover sprays under field conditions, and treated plants bearing fruit were transferred to large cages and exposed to fruit flies. Efficacy was assessed in terms of numbers of pupae developing from treated fruit. A laboratory cage method was also used to assess effects on adult mortality and comparative effects of 1- and 3-d-aged residues. The neonicotinoids clothianidin and thiacloprid were very effective against $B$. tryoni and $Z$. cucumis. Clothianidin was the only insecticide other than dimethoate to affect adult mortality. The synthetic pyrethroid alpha-cypermethrin was also very effective, particularly in semifield trials, although higher incidence of aphid and whitefly infestation was observed in this treatment compared to others. Cyantraniliprole was effective against $B$. tryoni, but less effective against $Z$. cucumis. Imidacloprid, bifenthrin, spinetoram, and abamectin were all relatively less effective, although all demonstrated a suppressive effect.
\end{abstract}

Key words: Bactrocera tryoni, Zeugodacus cucumis, Tephritidae, insecticide

Tephritid fruit flies are serious pests of horticultural crops in Australia. Bactrocera tryoni (Froggatt) attacks a wide range of fruit and vegetable crops in eastern Australia (Drew et al. 1982, Hancock et al. 2000), causing crop loss and threatening market access. There have been increasingly frequent incursions of this pest into the Fruit Fly Exclusion Zone in the southern states of Australia (Dominiak et al. 2015). Zeugodacus cucumis (French) causes damage to cucurbit crops and tomatoes in Queensland, northern New South Wales, the Northern Territory, and Torres Strait Islands (Drew et al. 1982, Hancock et al. 2000).

In Australia, in-field management of fruit flies in fruiting vegetable crops has relied almost exclusively on organophosphate cover sprays. However, recent restrictions in the use of dimethoate (Australian Pesticides and Veterinary Medicines Authority [APVMA] 2011, APVMA 2017) and fenthion (APVMA 2015) have greatly limited the available control options. While the use of dimethoate for control of fruit fly in certain fruiting vegetable crops has been retained (e.g. capsicum, melons, zucchini), for others it has been suspended from use, or the withholding period extended rendering it largely ineffective. Alternative approaches for managing fruit fly in host crops have been explored, such as the use of toxic baits and male annihilation technique (Clarke et al. 2011, Vargas et al. 2015). However, development of these management methods has primarily been focused on tree crops, or exotic tephritid species in vegetable crops. For instance, perimeter baiting, in which a protein bait plus insecticide is applied to a nonhost plant adjacent to the crop, is a commonly used technique for management of melon fly, Zeugodacus cucurbitae (Coquillett) in Hawaii (McQuate 2011). It exploits the observation that $Z$. cucurbitae females roost and forage for protein in certain favoured nonhost plants (Nishida and Bess 1957, Prokopy et al. 2003). The efficacy of toxic baits for control of B. tryoni and Z. cucumis in fruiting vegetable crops is currently unproven. Moreover, vegetable crops are often subject to intensive insecticide regimes for management of other pest species, and it is important to understand the potential impact of these insecticides on fruit flies.

A number of studies have examined the toxicity of pesticides to tephritid fruit flies in the laboratory using a range of methods such as direct application to adult flies (Wang et al. 2013), exposure to residues on artificial substrates (Mosleh et al. 2011), exposure to residues on fruit applied and aged in the laboratory (Maklakov et al. 
2001, Yee 2008, Yee and Alston 2012) or the field (Yee et al. 2007, Rahman and Broughton 2016), or application of insecticide sprays to infested fruit (Wise et al. 2009). Small plot field trials have been employed to assess efficacy of insecticides for management of cucurbit-specific fruit flies such as Z. cucurbitae in cucurbits (Oke 2008, Khursheed and Raj 2012, Oke and Sinon 2013), and field trials conducted in tree crops for management of Rhagoletis spp. (Reissig 2003, Yee and Alston 2006). However, the literature on insecticide efficacy for B. tryoni and Z. cucumis is scarce. Reynolds et al. (2014) compared insecticides for efficacy against B. tryoni in the laboratory and in semifield trials in stonefruit, in which fruit flies were introduced into mesh sleeves enclosing treated fruit on peach trees. Subramaniam (2013) evaluated insecticide cover sprays for management of B. tryoni in eggplant; however, efficacy formed part of a systems approach and was not compared with a control. Kay (2004) assessed efficacy of insecticides against B. tryoni in a small plot field trial in capsicum, but failed to find significant differences amongst treatments due to high variability of infestation across replicate plots. Atuahene and Hooper (1971) investigated the susceptibility of B. tryoni and Z. cucumis to DDT, with no recent literature relating to the efficacy of insecticides against the latter species.

Laboratory trials can provide useful information on relative efficacy of insecticides but are limited by their artificial nature (Macfadyen et al. 2014). When insecticides are applied directly or insects are confined in close contact with residues, repellent effects cannot be measured. Laboratory trials often provide no information on the insecticide's performance in the field, such as resistance to weathering, movement within the plant, or the effect of nonuniform application.

Small plot field trials are the conventional method used for many horticultural pests to assess comparative efficacy of insecticides under field conditions. However, there is evidence that because B. tryoni invades low growing crops from the field margins, this results in a typically uneven infestation in such crops. Balagawi et al. (2014) recorded higher numbers of male B. tryoni in traps placed in vegetation bordering a strawberry crop than traps within the crop, and from the same study $\mathrm{Gu}$ (2010) found rates of infestation were correspondingly higher in fruit near the border than within the crop. This makes it difficult to compare treatments within a trial area due to large variability between treatments and replicates, as observed in the small plot field trial performed by Kay (2004) to compare cover sprays for control of B. tryoni in capsicum. Kay (2004) speculated that the higher infestation in certain plots was due to proximity to bordering trees and a citrus block. Steiner and Hinman (1952) encountered similar difficulties in small plot tests in tree crops, noting that populations of oriental fruit fly, Bactrocera dorsalis (Hendel), in control plots were depressed by nearby treated plots, and that greater movement of fruit flies into the windward side of the trial area resulted in larger infestations in these plots.

Trials were carried out to compare insecticides as cover sprays for efficacy against B. tryoni and Z. cucumis under semifield conditions. The aims were twofold: first, to obtain information on the comparative efficacy of a series of insecticides, and second, to assess a novel semifield methodology. The insecticides were applied to crops in the ground, and therefore subject to actual use conditions. An artificial infestation method was then used to ensure all fruits from all treatments were subjected to a similar fruit fly pressure.

\section{Materials and Methods}

\section{Small Plot Trial Layout}

Semifield trials were conducted over two years to evaluate the efficacy of a range of insecticides against B. tryoni in capsicum,
Capsicum annuum (commercial variety Warlock), and Z. cucumis in zucchini, Cucurbita pepo (commercial variety Congo F1). Trials were conducted from January to April 2014 (season one) and January to April 2015 (season two) at Gatton Research Facility (Lockyer Valley, QLD, Australia; $27^{\circ} 32^{\prime}$ S, $152^{\circ} 19^{\prime}$ E, elevation $98 \mathrm{~m})$. Crops were planted in January into plastic mulch and irrigated using trickle tape. The trial layout was a randomized complete block design with seven treatments, replicated four times. Treatments were arranged lengthwise, with $2 \mathrm{~m}$ no-crop buffers between plots in the lengthwise direction, and $2 \mathrm{~m}$ no-crop buffers between replicate blocks. Between-plant spacings were $0.5 \mathrm{~m}$ for capsicum and $0.75 \mathrm{~m}$ for zucchinis. Each plot was on a 1.5 -m-wide bed and plot length varied according to season and crop: season one $9 \mathrm{~m}$ (14 capsicum plants) or $9.5 \mathrm{~m}$ (11 zucchini plants); season two $10 \mathrm{~m}$ (17 capsicum plants) or $10.5 \mathrm{~m}$ (12 zucchini plants). Rows of forage sorghum on either side of the trial block provided protection from wind and potential spray drift. Fungicides were applied for disease control: Polyram DF (BASF Australia Ltd, Southbank, VIC), Kocide Blue Xtra (Du Pont (Australia) Pty Ltd, Macquarie Park, NSW), and Dithane Rainshield Neo Tec Fungicide (Dow AgroSciences (Australia) Ltd, Frenchs Forest, NSW). In season one, the insecticides Transform (Dow AgroSciences (Australia) Ltd; active ingredient sulfoxaflor) and Talstar 250 EC (FMC Australasia Pty Ltd, Murarrie, QLD; active ingredient bifenthrin) were applied for control of whitefly and aphids. Application of these insecticides to young plants was made prior to the application of the trial treatments, and was not expected to affect the fruit flies.

\section{Treatments}

In each trial, five insecticide treatments were assessed and compared with dimethoate (the industry standard) applied at the rate of $75 \mathrm{ml} /$ 100 liter and with an untreated control. In season one (2014) the five insecticide treatments were Sumitomo Samurai Systemic Insecticide (Sumitomo Chemical Australia Pty Ltd, Epping, NSW; active ingredient clothianidin) applied at $40 \mathrm{~g} / 100$ liter; Confidor 200 SC (Bayer CropScience Pty Ltd, Hawthorn East, VIC; active ingredient imidacloprid) at $25 \mathrm{ml} / 100$ liter; Talstar 250 EC Insecticide/ Miticide (FMC Australasia Pty Ltd, Murarrie, QLD; active ingredient bifenthrin) at $24 \mathrm{ml} / 100$ liter; Fastac Duo Insecticide (BASF Australia Ltd, Baulkham Hills, NSW; active ingredient alphacypermethrin) at $55 \mathrm{ml} / 100$ liter; and DuPont Benevia Insecticide (Du Pont (Australia) Pty Ltd, Macquarie Park, NSW; active ingredient cyantraniliprole) at $100 \mathrm{ml} / 100$ liter. In season two (2015) the five insecticide treatments were Sumitomo Samurai Systemic Insecticide (Sumitomo Chemical Australia Pty Ltd; active ingredient clothianidin) applied at $40 \mathrm{~g} / 100$ liter and $30 \mathrm{~g} / 100$ liter; Calypso 480 SC Insecticide (Bayer CropScience Pty Ltd; active ingredient thiacloprid) at $37.5 \mathrm{ml} / 100$ liter; Vertimec Miticide/Insecticide (Syngenta Australia Pty Ltd, Macquarie Park, NSW; active ingredient abamectin) at $60 \mathrm{ml} / 100$ liter; and Success Neo Insecticide (Dow AgroSciences (Australia) Ltd; active ingredient spinetoram) at $40 \mathrm{ml} /$ 100 liter. Agral spray adjuvant (Syngenta Australia Pty Ltd) was added to all treatments at the rate of $10 \mathrm{ml} / 100$ liter, with the exception of the Samurai treatments, where Maxx Organosilicone Surfactant (Sumitomo Chemical Australia Pty Ltd) was used at the rate of $50 \mathrm{ml} / 100$ liter.

Insecticides were applied using a gas pressurised sprayer, with a 1.2-m four-nozzle boom. The spray was applied at an operating boom pressure of $\sim 230 \mathrm{kPa}$ and a volume of $700-760$ liter/ha (dependent on crop and plot size), achieved through two passes of each plot in order to ensure good coverage. Treatments were applied weekly from first fruit set onwards, until all trials had been 
Table 1. Dates of spray application and trials, season one (2014)

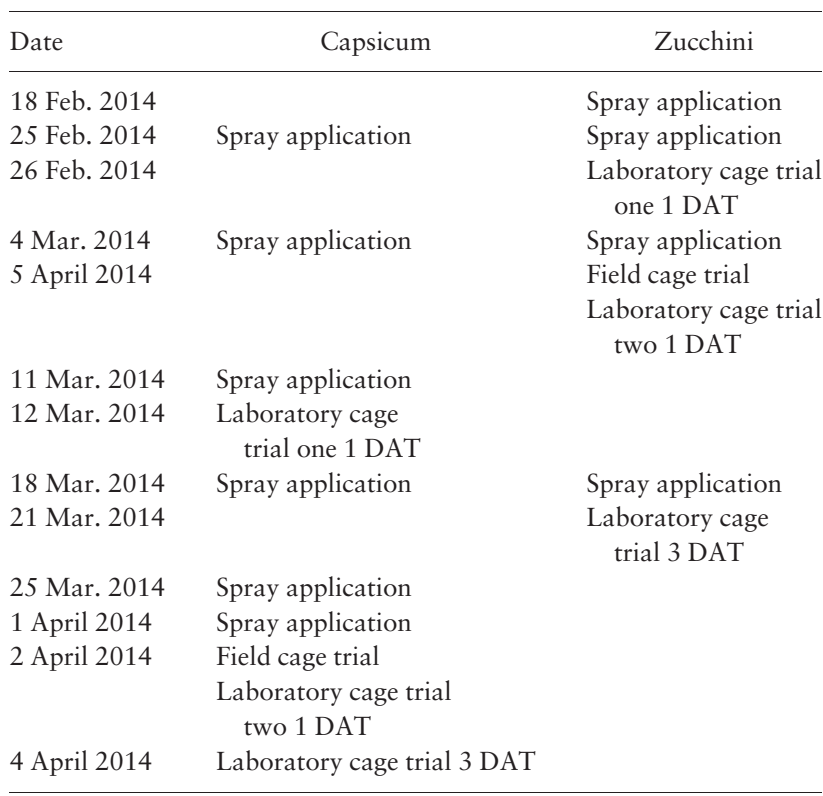

DAT_day after treatment.

completed, hence the number of treatment applications varied dependent on season and crop (Tables 1 and 2). In season one (2014) four applications were made to the zucchinis and six to the capsicums. In season two (2015) three applications were made to the zucchinis and five to the capsicums. However, due to the rapid rate of development of the zucchini fruit, it was necessary to remove large fruit at regular intervals to ensure continuous production; hence zucchini fruit used in trials had received a maximum of three applications.

Treated plants were exposed to fruit flies using two methods. First, fruit flies were exposed to intact fruit on plants removed from the field and placed into large field cages. Second, fruit flies were exposed to fruit in small laboratory cages, in order to assess adult mortality and efficacy of aged residues.

\section{Fruit Flies}

All fruit flies were obtained from colonies maintained by the Market Access research group at the Department of Agriculture and Fisheries (DAF) (Brisbane, QLD, Australia). Bactrocera tryoni colonies were established from collections of host fruit (Endiandra sp, Barringtonia calyptrata, and Terminalia catappa) in the Cairns region in January 2012 and reared according to the method of Heather and Corcoran (1985). Adults used in season one (2014) were $10-16 \mathrm{~d}$ post emergence and $16-18 \mathrm{~d}$ post emergence in season two (2015). Zeugodacus cucumis colonies were established from collections of zucchini in the Ayr and Cairns regions in September and October 2010. They were reared according to the method of Heather and Corcoran (1985) using the pumpkin diet described by Swaine et al. (1978). Zeugodacus cucumis were 13-15 d post emergence. Prior to use in the tests all fruit flies were provided with sugar, water, and protein (autolysed yeast) and allowed to mate, hence were ready to oviposit.

\section{Field Cage Infestation}

Trials were performed in four metal frame, netted cages $(3 \mathrm{~m}$ by $3 \mathrm{~m}$ base, $2.5 \mathrm{~m}$ high), each cage representing one replicate. One day following treatment application, treated plants bearing fruit were
Table 2. Dates of spray application and trials, season two (2015)

\begin{tabular}{|c|c|c|}
\hline Date & Capsicum & Zucchini \\
\hline 24 Feb. 2015 & & Spray application \\
\hline 3 Mar. 2015 & Spray application & Spray application \\
\hline 4 Mar. 2015 & & Field cage trial \\
\hline 10 Mar. 2015 & Spray application & Spray application \\
\hline 11 Mar. 2015 & & Laboratory cage trial $1 \mathrm{DAT}$ \\
\hline 13 Mar. 2015 & & Laboratory cage trial 3 DAT \\
\hline 17 Mar. 2015 & Spray application & \\
\hline 24 Mar. 2015 & Spray application & \\
\hline 25 Mar. 2015 & $\begin{array}{l}\text { Laboratory cage } \\
\text { trial } 1 \text { DAT }\end{array}$ & \\
\hline 27 Mar. 2015 & $\begin{array}{l}\text { Laboratory cage } \\
\text { trial } 3 \text { DAT }\end{array}$ & \\
\hline 31 Mar. 2015 & Spray application & \\
\hline 1 April 2015 & Field cage trial & \\
\hline
\end{tabular}

DAT—day after treatment.

selected at random from each replicate of each treatment, dug up, placed in large pots, watered and transferred to the field cages. Fruit flies were therefore exposed to residues on the foliage as well as on the fruit. Three zucchini plants or four capsicum plants were used per treatment replicate, with plants from each treatment grouped together, meaning that all seven treatments were present in each replicate cage. Approximately 600 mixed sex adult fruit flies, determined by pupal weight, were released into each cage. In the first season trial, all fruit flies were left for $\sim 4 \mathrm{~h}$ to oviposit. In the second season trial, based on results from the first season, the exposure time was decreased to $3 \mathrm{~h}$ for $Z$. cucumis, and due to adverse weather conditions (cool with light rain), B. tryoni were left to oviposit overnight $(\sim 20-21 \mathrm{~h})$. Fruit were then harvested and transported to the laboratory for subsequent assessment of infestation. The size and number of fruit per treatment replicate varied between replicates and treatments, due to variable fruit production of the plants. Therefore, fruit in each treatment replicate were weighed (not counted), and the weight range for each of the field cage trials presented in the results.

In the laboratory, the harvested fruit from each treatment replicate were placed on shallow plastic containers covered with net, within ventilated containers. A layer of vermiculite on the base of the container was provided as a substrate for pupation. The fruit were held in a controlled environment room $\left(26^{\circ} \mathrm{C}, 70 \%\right.$ relative humidity) for $\sim 2$ wk to allow any eggs laid to develop to the pupal stage. The vermiculite was then sieved and the number of pupae counted. Additional fruit were harvested from untreated control plants in the trial block to assess the level of infestation in the field, prior to artificial infestation in the field cages. However, no pupae developed from any of these fruit and therefore these results were not included in the analyses.

\section{Laboratory Cage Infestation}

Fruit were removed from plants in the trial plots either 1 or $3 \mathrm{~d}$ after treatment application ( 1 and 3 DAT). Two 1 DAT and one 3 DAT laboratory cage trials were conducted for the first season; one 1 DAT and one 3 DAT trial were conducted for the second season. Bifenthrin (Talstar 250 EC Insecticide/Miticide) was omitted from the 3 DAT first season cucumber fly trial due to poor efficacy at 1 DAT. Three fruit from each treatment replicate were exposed to fruit flies in small laboratory cages (wire frame, netted cages, $21 \mathrm{~cm}$ wide, $21 \mathrm{~cm}$ high, $33 \mathrm{~cm}$ deep). Each cage contained 10 male and 


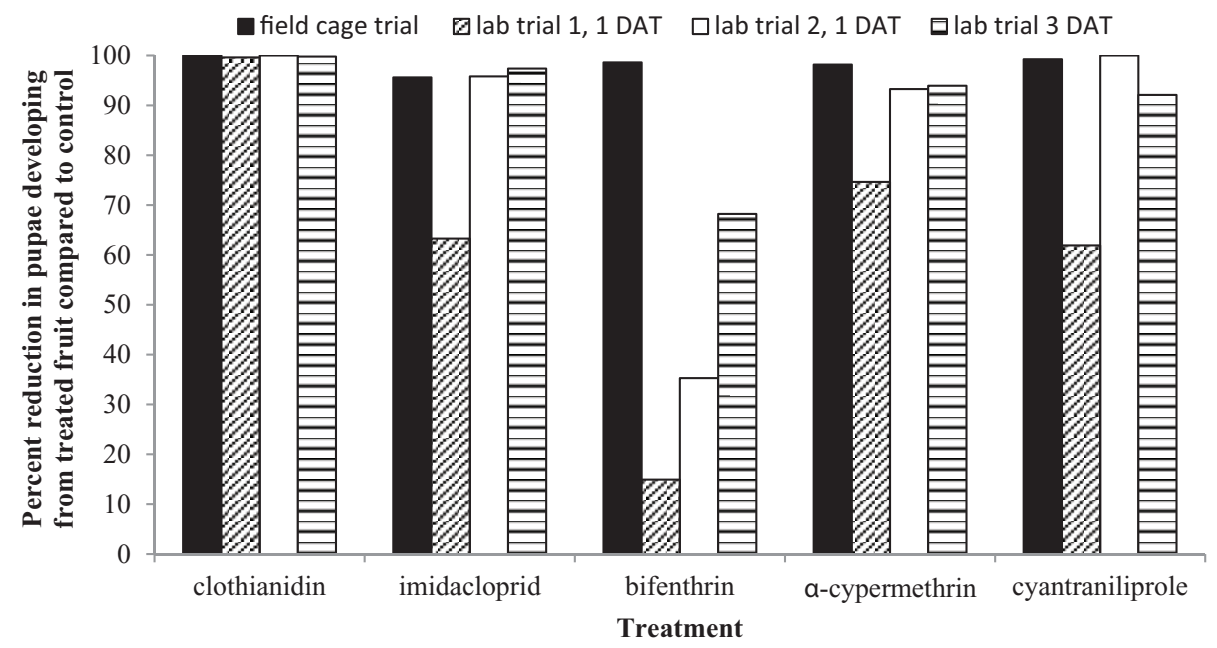

Fig. 1. Effect of treatments on reduction in numbers of $B$. tryoni pupae developing from treated capsicum compared with control fruit in season one trials.

10 female fruit flies, provided with sugar and water. Exposure times varied dependent on the fruit type, fruit fly species, and time of day that fruit were harvested. In season one, zucchinis in the 1 DAT trials were picked and placed into cages in the afternoon, and hence infested overnight (13 and $18 \mathrm{~h}$ infestation periods). This was reduced to $3 \mathrm{~h}$ for the 3 DAT trial. Capsicums were infested for $3 \mathrm{~h}$ (1 DAT trial one), overnight ( $\sim 15 \mathrm{~h}, 1$ DAT trial two) or $2.5 \mathrm{~h}$ (3 DAT trial). In season two, exposure was reduced due to overinfestation in season one, and all laboratory cage trial fruit was infested for between 2 and $3 \mathrm{~h}$. Following exposure to the fruit flies, fruit were held in ventilated containers under controlled conditions as described previously, and the number of pupae counted. Mortality of adult fruit flies was assessed $1 \mathrm{~d}(\sim 24 \mathrm{~h})$ after placement of fruit into the cages.

\section{Statistical Analyses}

Numbers of pupae developing from the fruit were analyzed using a generalized linear mixed model (GLMM) assuming a Poisson distribution and a log link function. Due to variability in number and size of fruit sampled from each replicate of each treatment, fruit weight was initially used as a covariate in the field cage analyses. However, with the exception of season one (2014) trial with B. tryoni in capsicum, the effect of fruit weight was found to be not significant and therefore removed. Where a significant effect of treatment was found, pairwise comparisons between the transformed means were made using the $95 \%$ least significant difference (LSD). In some instances, no pupae developed in a treatment, or pupae developed in only one replicate of a treatment, resulting in an overinflated standard error. Means with an overinflated standard error were not included in the pairwise comparisons; however, when no pupae developed we can intuitively say that there was a significant effect of treatment. Control corrected means (Abbott 1925) were also calculated and presented to facilitate comparison of treatment efficacy.

The proportion of dead fruit flies at one day after exposure to the treated fruit was analyzed using a GLMM assuming a binomial distribution and logit link function. Where a significant treatment effect was found, pairwise comparisons between the transformed means were made using the $95 \%$ LSD. Mortality was expressed as the mean number of dead fruit flies per cage for presentation in results.

Statistical analyses were performed in GenStat for Windows $16^{\text {th }}$ Edition (VSN International 2013).

\section{Results}

\section{Season One (2014) B. tryoni in Capsicum}

Results of a field cage trial found a significant effect of treatment on development of pupae from treated fruit $(P=0.002$; Table 3$)$. All insecticide treatments resulted in significantly fewer pupae than the control. Weight of fruit harvested from each replicate of each treatment varied between $908 \mathrm{~g}$ and $1984 \mathrm{~g}$. The first 1 DAT laboratory cage trial and the 3 DAT laboratory cage trial both found a significant effect of treatment $(P<0.001)$, with significantly fewer pupae in all treatments compared to the control at 3 DAT and significantly fewer pupae in all treatments except bifenthrin compared to the control at 1 DAT. There was no significant effect of treatment in the second laboratory cage trial $(P>0.05)$, due in part to large variability in the control treatment (pupal counts ranged from 0 to 108). The effect of treatment on development of pupae from treated fruit was also expressed as control corrected means (Fig. 1). Clothianidin consistently resulted in circa $100 \%$ reduction in development of pupae in all four trials; imidacloprid, alpha-cypermethrin, and cyantraniliprole resulted in greater than $90 \%$ reduction in development of pupae in three of the four trials; and bifenthrin was effective only in the field cage trial.

Mortality of the adult fruit flies in the laboratory cage trials was assessed at $\sim 24 \mathrm{~h}$ (Table 4 ). There was a significant effect of treatment on fruit flies exposed to 1 -d residues (1 DAT), in both trials $(P \leq 0.011)$, with significantly higher mortality in the dimethoate treatment compared to the control, and in the clothianidin treatment compared to the control in the first trial only. Three-day-old residues had no significant effect on mortality of the adult fruit flies $(P>0.05)$.

\section{Season One (2014) Z. cucumis in Zucchini}

Results of a field cage trial found a significant effect of treatment on the number of pupae developing from the fruit $(P=0.011$; Table 5). Clothianidin, alpha-cypermethrin, cyantraniliprole, and dimethoate resulted in significantly fewer pupae compared to the untreated control. Weight of fruit harvested from each replicate of each treatment varied between $892 \mathrm{~g}$ and $1200 \mathrm{~g}$. Two laboratory cage trials conducted at 1 DAT and a laboratory cage trial at 3 DAT all found a significant effect of treatment $(P \leq 0.004)$. Clothianidin and dimethoate consistently resulted in the fewest pupae, and bifenthrin 
Table 3. Mean number of pupae developing from capsicum exposed to $B$. tryoni in season one trials; back-transformed means (BTM) and predicted means on the log scale \pm 1 standard error (PM)

\begin{tabular}{|c|c|c|c|c|c|c|c|c|}
\hline \multirow[t]{2}{*}{ Treatment } & \multicolumn{2}{|c|}{ Field cage trial, 1 DAT } & \multicolumn{2}{|c|}{ Lab cage trial 1,1 DAT } & \multicolumn{2}{|c|}{ Lab cage trial 2,1 DAT } & \multicolumn{2}{|c|}{ Lab cage trial, 3 DAT } \\
\hline & BTM & PM & BTM & PM & BTM & PM & BTM & PM \\
\hline Clothianidin & 0.0 & $-16.82 \pm \delta$ & $0.5 \mathrm{a}$ & $-0.69 \pm 1.90$ & 0.0 & $-16.48 \pm \delta$ & 0.3 & $-1.39 \pm \delta$ \\
\hline Imidacloprid & $3.1 \mathrm{a}$ & $1.12 \pm 1.13$ & $46.7 \mathrm{~b}$ & $3.84 \pm 0.20$ & 0.7 & $-0.32 \pm 1.66$ & $3.3 \mathrm{a}$ & $1.18 \pm 1.28$ \\
\hline Bifenthrin & $1.0 \mathrm{a}$ & $-0.02 \pm 1.62$ & $108.2 \mathrm{c}$ & $4.68 \pm 0.14$ & 11.1 & $2.41 \pm 0.80$ & $39.3 a$ & $3.67 \pm 0.37$ \\
\hline$\alpha$-Cypermethrin & $1.3 \mathrm{a}$ & $0.24 \pm 1.65$ & $32.2 \mathrm{~b}$ & $3.47 \pm 0.24$ & 1.2 & $0.15 \pm 1.38$ & $7.5 \mathrm{a}$ & $2.02 \pm 0.85$ \\
\hline Cyantraniliprole & $0.5 \mathrm{a}$ & $-0.63 \pm 2.22$ & $48.5 b$ & $3.88 \pm 0.20$ & 0.0 & $-16.48 \pm \delta$ & $9.8 \mathrm{a}$ & $2.28 \pm 0.74$ \\
\hline Dimethoate & $1.0 \mathrm{a}$ & $-0.04 \pm 1.63$ & $24.0 \mathrm{ab}$ & $3.18 \pm 0.28$ & 1.3 & $0.26 \pm 1.32$ & $7.3 \mathrm{a}$ & $1.98 \pm 0.86$ \\
\hline Untreated control & $70.2 \mathrm{~b}$ & $4.25 \pm 0.48$ & $127.2 \mathrm{c}$ & $4.85 \pm 0.13$ & 17.2 & $2.85 \pm 0.77$ & $123.5 b$ & $4.82 \pm 0.21$ \\
\hline \multirow[t]{3}{*}{ GLMM } & & 5.41 & & 12.59 & & 2.10 & & 6.31 \\
\hline & & $6,17.7$ & & 6,20 & & $6,18.2$ & & 6,21 \\
\hline & & 0.002 & & $<0.001$ & & 0.104 & & $<0.001$ \\
\hline
\end{tabular}

Means with a letter in common are not significantly different (LSD test; $P>0.05$ ).

$\delta$ indicates an overinflated standard error.

Table 4. Mean mortality per cage of 20 adult $B$. tryoni exposed to insecticide residues on capsicum in season one trials; back transformed means (BTM) and predicted means on the logit scale \pm 1 standard error (PM)

\begin{tabular}{|c|c|c|c|c|c|c|c|}
\hline \multirow{2}{*}{\multicolumn{2}{|c|}{ Treatment }} & \multicolumn{2}{|c|}{ Lab cage trial 1,1 DAT } & \multicolumn{2}{|c|}{ Lab cage trial 2, 1 DAT } & \multicolumn{2}{|c|}{ Lab cage trial, 3 DAT } \\
\hline & & BTM & $\mathrm{PM}$ & BTM & PM & BTM & PM \\
\hline \multicolumn{2}{|c|}{ Clothianidin } & $5.5 \mathrm{~d}$ & $-0.97 \pm 0.24$ & $3.5 \mathrm{bc}$ & $-1.55 \pm 0.38$ & 1.5 & $-2.51 \pm 0.48$ \\
\hline \multicolumn{2}{|c|}{ Imidacloprid } & $0.5 \mathrm{a}$ & $-3.66 \pm 0.68$ & $1.5 \mathrm{ab}$ & $-2.51 \pm 0.54$ & 1.5 & $-2.51 \pm 0.48$ \\
\hline \multicolumn{2}{|c|}{ Bifenthrin } & $2.5 \mathrm{bc}$ & $-1.95 \pm 0.32$ & $0.5 \mathrm{a}$ & $-3.66 \pm 0.91$ & 0.5 & $-3.66 \pm 0.80$ \\
\hline \multicolumn{2}{|c|}{$\alpha$-Cypermethrin } & $1.3 \mathrm{ab}$ & $-2.71 \pm 0.44$ & $0.5 \mathrm{a}$ & $-3.66 \pm 0.91$ & 1.5 & $-2.51 \pm 0.48$ \\
\hline \multicolumn{2}{|c|}{ Cyantraniliprole } & $1.8 \mathrm{ab}$ & $-2.35 \pm 0.38$ & $1.5 \mathrm{ab}$ & $-2.51 \pm 0.54$ & 1.5 & $-2.51 \pm 0.48$ \\
\hline \multicolumn{2}{|c|}{ Dimethoate } & $4.8 \mathrm{~cd}$ & $-1.17 \pm 0.25$ & $5.5 \mathrm{c}$ & $-0.97 \pm 0.32$ & 3.3 & $-1.64 \pm 0.34$ \\
\hline \multicolumn{2}{|c|}{ Untreated control } & $1.8 \mathrm{ab}$ & $-2.35 \pm 0.38$ & $0.8 \mathrm{ab}$ & $-3.25 \pm 0.75$ & 2.0 & $-2.20 \pm 0.42$ \\
\hline \multirow[t]{3}{*}{ GLMM } & $F$ & \multicolumn{2}{|c|}{5.62} & \multicolumn{2}{|c|}{3.76} & \multicolumn{2}{|c|}{1.25} \\
\hline & $\mathrm{df}$ & \multicolumn{2}{|c|}{6,21} & \multicolumn{2}{|c|}{6,21} & \multicolumn{2}{|c|}{6,21} \\
\hline & $P$ & \multicolumn{2}{|c|}{0.001} & \multicolumn{2}{|c|}{0.011} & \multicolumn{2}{|c|}{0.320} \\
\hline
\end{tabular}

Means with a letter in common are not significantly different (LSD test; $P>0.05$ ).

was ineffective. Only clothianidin resulted in over $90 \%$ reduction in development of pupae in all four trials (Fig. 2).

There was a significant effect of treatment on adult fruit fly mortality in all three laboratory cage trials $(P<0.001$; Table 6). Mortality was highest in the dimethoate and clothianidin treatments at 1 DAT, and in the dimethoate treatment at 3 DAT.

Although not quantified, it was observed that occurrence of aphids (Myzus persicae and Aphis gossypii) and sweetpotato whitefly (Bemisia tabaci) was much higher in plots treated with alphacypermethrin, bifenthrin, and dimethoate compared with other treatments.

\section{Season Two (2015) B. tryoni in Capsicum}

Results of a field cage trial found no significant effect of treatment on the development of pupae from treated fruit $(P>0.05$; Table 7$)$. Weight of fruit harvested from each replicate of each treatment varied between $421 \mathrm{~g}$ and $2836 \mathrm{~g}$. Laboratory cage trials at 1 DAT and 3 DAT both found a significant effect of treatment $(P \leq 0.018)$, with no pupae developing in the clothianidin treatments, and significantly fewer pupae in the thiacloprid and dimethoate treatments compared to the control. In addition, pupal counts were significantly lower than the control for abamectin in the 1 DAT trial and spinetoram in the 3 DAT trial. Only the higher rate of clothianidin $(40 \mathrm{~g} / 100$ liter $)$ and thiacloprid resulted in greater than $90 \%$ reduction in development of pupae in all three trials (Fig. 3).

There was a significant effect of treatment on adult fruit fly mortality in both the 1 DAT and 3 DAT laboratory cage trials $(P \leq 0.007$; Table 8$)$. Significantly higher mortality compared to other treatments was observed for dimethoate and both rates of clothianidin, in both trials.

\section{Season Two (2015) Z. cucumis in Zucchini}

Results of a field cage trial found no significant effect of treatment on the number of pupae developing from the zucchinis $(P>0.05$; Table 9). Weight of fruit harvested from each replicate of each treatment varied between $1172 \mathrm{~g}$ and $2696 \mathrm{~g}$. Laboratory cage trials at 1 DAT found a significant effect of treatment on number of pupae developing from the fruit $(P<0.001)$, with significantly fewer pupae in all treatments compared to the untreated control. Clothianidin and dimethoate resulted in the fewest pupae, and abamectin was the least effective treatment. There was no significant effect of treatment for 3 DAT residues $(P>0.05)$. Only clothianidin resulted in close to $100 \%$ reduction in development of pupae in all three trials (Fig. 4).

There was a significant effect of treatment on adult fruit fly mortality in both the 1 DAT and 3 DAT laboratory cage trials $(P \leq 0.008$; Table 10). The highest mortality was observed in the clothianidin and dimethoate treatments. 


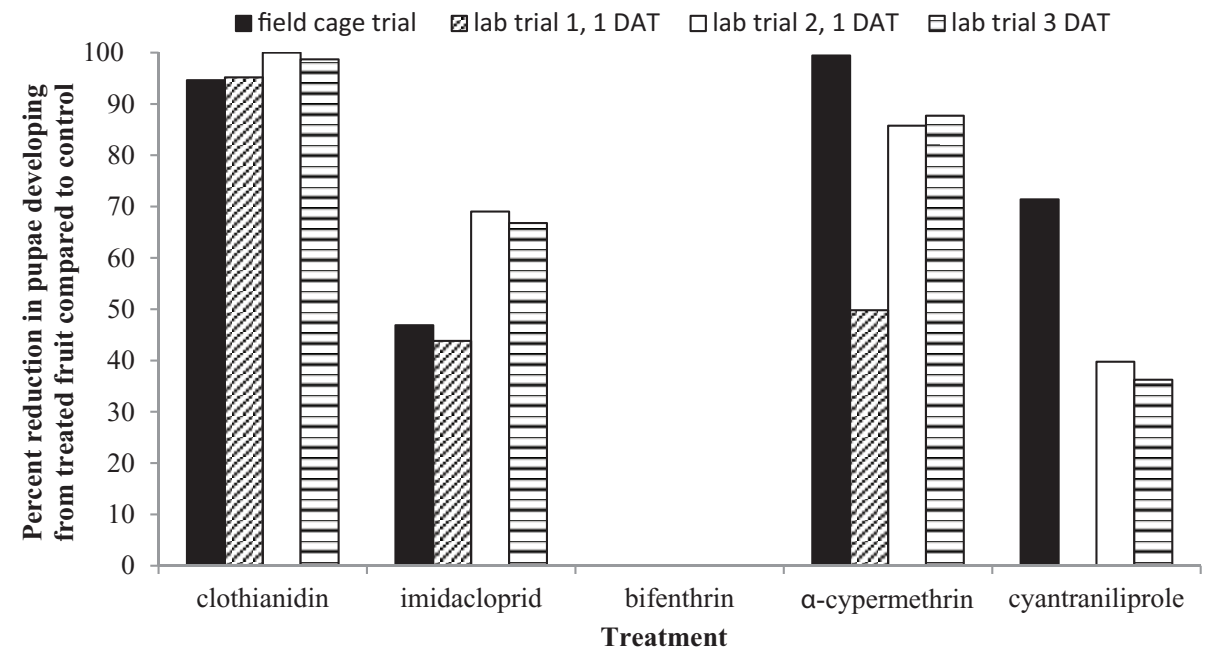

Fig. 2. Effect of treatments on reduction in numbers of Z. cucumis pupae developing from treated zucchini compared with control fruit in season one trials.

Table 5. Mean number of pupae developing from zucchini exposed to Z. cucumis in season one trials; back-transformed means (BTM) and predicted means on the log scale \pm 1 standard error (PM)

\begin{tabular}{|c|c|c|c|c|c|c|c|c|}
\hline \multirow[t]{2}{*}{ Treatment } & \multicolumn{2}{|c|}{ Field cage trial, 1 DAT } & \multicolumn{2}{|c|}{ Lab cage trial 1,1 DAT } & \multicolumn{2}{|c|}{ Lab cage trial 2, 1 DAT } & \multicolumn{2}{|c|}{ Lab cage trial, 3 DAT } \\
\hline & BTM & PM & BTM & PM & BTM & PM & BTM & PM \\
\hline Clothianidin & $23.4 \mathrm{a}$ & $3.16 \pm 1.21$ & $20.5 \mathrm{a}$ & $3.02 \pm 0.92$ & 0.0 & $-8.69 \pm \delta$ & $11.0 \mathrm{a}$ & $2.40 \pm 0.97$ \\
\hline Imidacloprid & $231.5 \mathrm{ab}$ & $5.45 \pm 0.49$ & $238.6 \mathrm{~b}$ & $5.48 \pm 0.29$ & $177.0 \mathrm{c}$ & $5.18 \pm 0.19$ & $281.2 \mathrm{c}$ & $5.64 \pm 0.19$ \\
\hline Bifenthrin & $601.7 \mathrm{c}$ & $6.40 \pm 0.39$ & $432.0 \mathrm{~b}$ & $6.07 \pm 0.23$ & $590.8 \mathrm{e}$ & $6.38 \pm 0.10$ & & a \\
\hline$\alpha$-Cypermethrin & 2.5 & $0.91 \pm \delta$ & $213.1 b$ & $5.36 \pm 0.31$ & $81.5 \mathrm{~b}$ & $4.40 \pm 0.28$ & $104.0 \mathrm{~b}$ & $4.64 \pm 0.32$ \\
\hline Cyantraniliprole & $124.7 \mathrm{a}$ & $4.83 \pm 0.60$ & $432.0 \mathrm{~b}$ & $6.07 \pm 0.23$ & $344.5 \mathrm{~d}$ & $5.84 \pm 0.14$ & $539.6 \mathrm{~d}$ & $6.29 \pm 0.14$ \\
\hline Dimethoate & $18.7 \mathrm{a}$ & $2.93 \pm 1.35$ & $50.4 \mathrm{a}$ & $3.92 \pm 0.59$ & $17.8 \mathrm{a}$ & $2.88 \pm 0.60$ & $17.2 \mathrm{a}$ & $2.85 \pm 0.77$ \\
\hline Untreated control & $435.8 b c$ & $6.08 \pm 0.41$ & $424.6 b$ & $6.05 \pm 0.23$ & $571.8 \mathrm{e}$ & $6.35 \pm 0.11$ & $846.6 \mathrm{e}$ & $6.74 \pm 0.11$ \\
\hline \multirow{3}{*}{ GLMM } & \multicolumn{2}{|c|}{3.92} & \multicolumn{2}{|c|}{4.83} & \multicolumn{2}{|r|}{17.22} & \multicolumn{2}{|r|}{18.28} \\
\hline & \multicolumn{2}{|c|}{$6,17.9$} & \multicolumn{2}{|c|}{$6,17.8$} & \multicolumn{2}{|r|}{6,21} & \multicolumn{2}{|r|}{5,15} \\
\hline & \multicolumn{2}{|c|}{0.011} & \multicolumn{2}{|c|}{0.004} & \multicolumn{2}{|r|}{$<0.001$} & \multicolumn{2}{|c|}{$<0.001$} \\
\hline
\end{tabular}

Means with a letter in common are not significantly different (LSD test; $P>0.05$ ).

$\delta$ indicates an overinflated standard error.

${ }^{a}$ Bifenthrin was omitted from the 3 DAT trial due to poor results in the 1 DAT trials.

Table 6. Mean mortality per cage of 20 adult $Z$. cucumis exposed to insecticide residues on zucchini in season one trials; back transformed means (BTM) and predicted means on the logit scale \pm 1 standard error (PM)

\begin{tabular}{|c|c|c|c|c|c|c|c|}
\hline \multirow{2}{*}{\multicolumn{2}{|c|}{ Treatment }} & \multicolumn{2}{|c|}{ Lab cage trial 1,1 DAT } & \multicolumn{2}{|c|}{ Lab cage trial 2, 1 DAT } & \multicolumn{2}{|c|}{ Lab cage trial, 3 DAT } \\
\hline & & BTM & PM & BTM & PM & BTM & PM \\
\hline \multicolumn{2}{|c|}{ Clothianidin } & $9.0 \mathrm{~b}$ & $-0.20 \pm 0.48$ & $5.7 \mathrm{~b}$ & $-0.91 \pm 0.27$ & $1.7 \mathrm{a}$ & $-2.35 \pm 0.44$ \\
\hline \multicolumn{2}{|c|}{ Imidacloprid } & $1.0 \mathrm{a}$ & $-2.93 \pm 0.65$ & $0.3 \mathrm{a}$ & $-4.38 \pm 0.96$ & $0.3 \mathrm{a}$ & $-4.38 \pm 1.08$ \\
\hline \multicolumn{2}{|c|}{ Bifenthrin } & $0.2 \mathrm{a}$ & $-4.62 \pm 1.15$ & $0.5 \mathrm{a}$ & $-3.67 \pm 0.69$ & & $a$ \\
\hline \multicolumn{2}{|c|}{$\alpha$-Cypermethrin } & $0.6 \mathrm{a}$ & $-3.48 \pm 0.76$ & $1.7 \mathrm{a}$ & $-2.35 \pm 0.40$ & $0.3 \mathrm{a}$ & $-4.38 \pm 1.08$ \\
\hline \multicolumn{2}{|c|}{ Cyantraniliprole } & $0.6 \mathrm{a}$ & $-3.48 \pm 0.76$ & 0.0 & $-16.75 \pm \delta$ & 0.0 & $-16.75 \pm \delta$ \\
\hline \multicolumn{2}{|c|}{ Dimethoate } & $3.4 \mathrm{~b}$ & $-1.60 \pm 0.52$ & $7.5 b$ & $-0.51 \pm 0.25$ & $11.0 \mathrm{~b}$ & $0.20 \pm 0.27$ \\
\hline \multicolumn{2}{|c|}{ Untreated control } & 0.0 & $-17.71 \pm \delta$ & $0.3 \mathrm{a}$ & $-4.38 \pm 0.96$ & 0.0 & $-16.75 \pm \delta$ \\
\hline \multirow[t]{3}{*}{ GLMM } & $F$ & \multicolumn{2}{|c|}{9.95} & \multicolumn{2}{|c|}{9.36} & \multicolumn{2}{|r|}{10.64} \\
\hline & df & \multicolumn{2}{|c|}{$6,18.2$} & \multicolumn{2}{|c|}{$6,17.9$} & \multicolumn{2}{|r|}{6,15} \\
\hline & $P$ & \multicolumn{2}{|c|}{$<0.001$} & \multicolumn{2}{|c|}{$<0.001$} & \multicolumn{2}{|r|}{$<0.001$} \\
\hline
\end{tabular}

Means with a letter in common are not significantly different (LSD test; $P>0.05$ ).

$\delta$ indicates an overinflated standard error.

${ }^{a}$ Bifenthrin was omitted from the 3 DAT trial due to poor results in the 1 DAT trials. 
Table 7. Mean number of pupae developing from capsicum exposed to B. tryoni in season two trials; back-transformed means (BTM) and predicted means on the log scale \pm 1 standard error (PM)

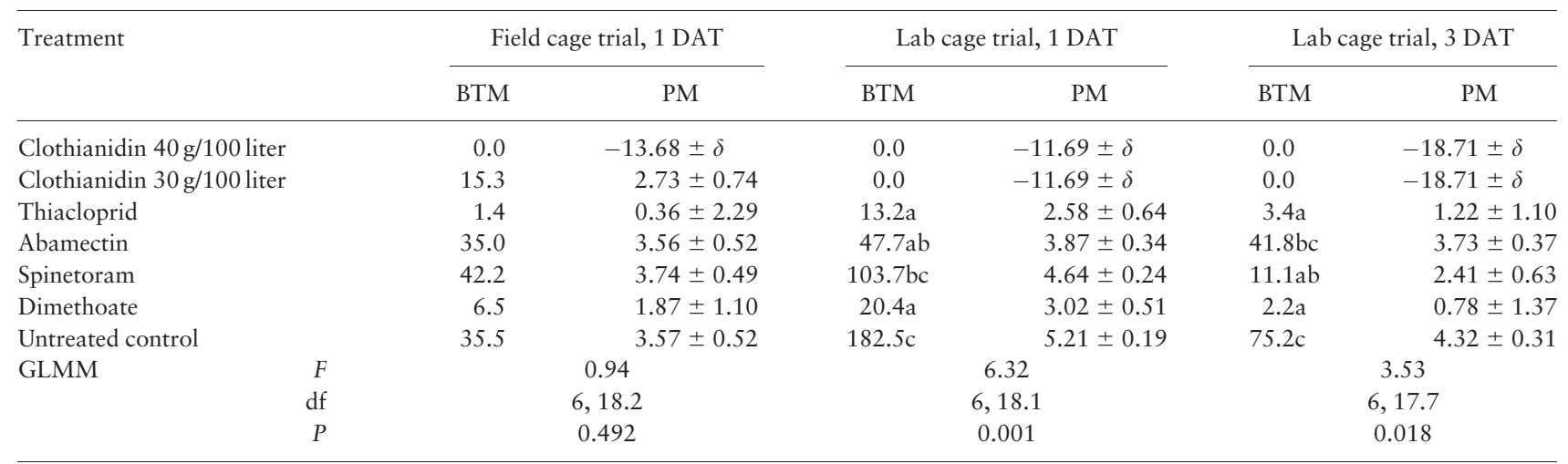

Means with a letter in common are not significantly different (LSD test; $P>0.05$ ).

$\delta$ indicates an overinflated standard error.

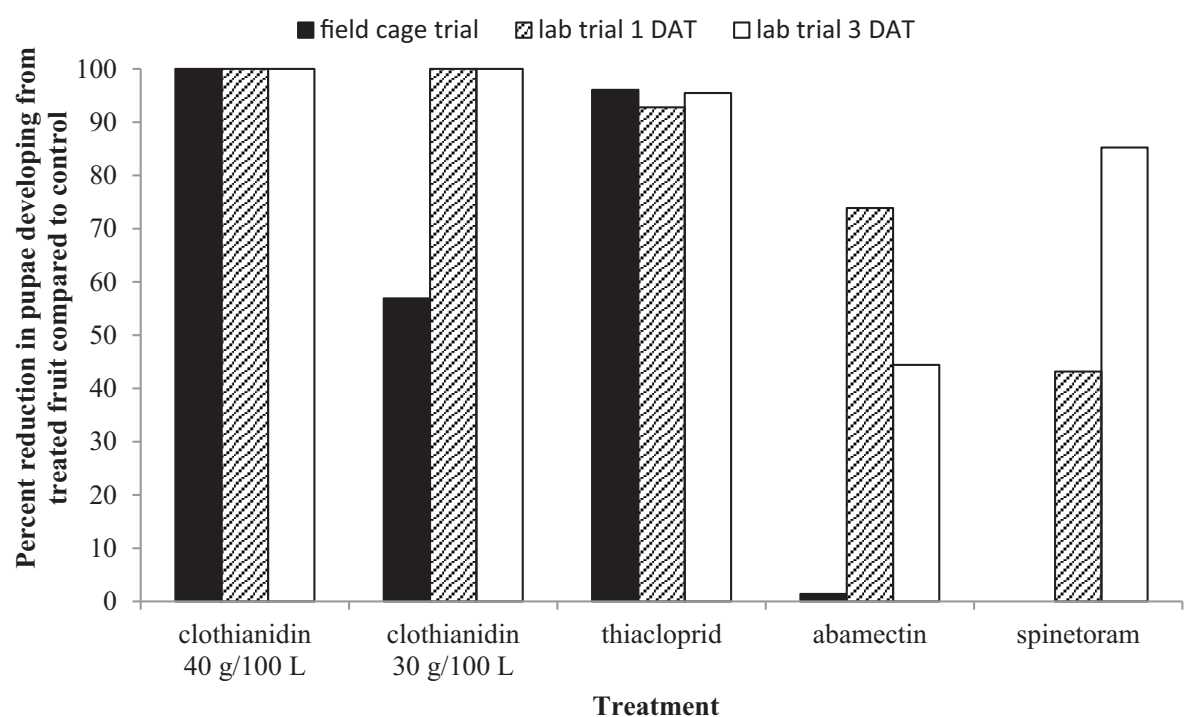

Fig. 3. Effect of treatments on reduction in numbers of $B$. tryoni pupae developing from treated capsicum compared with control fruit in season two trials.

\section{Weather Data}

Rainfall for the 2014 trial period was minimal except for a period following the penultimate spray application made to capsicum (25th March). Rainfall during the 2015 trial period was minimal in the 48-h periods following spray applications with the exception of those applied to capsicum on 17th and 24th March.

\section{Discussion}

All the insecticides demonstrated some level of efficacy compared to the untreated control. Efficacy was generally lower for Z. cucumis than B. tryoni. This may in part have been because the zucchinis developed more quickly than capsicums, were picked more frequently and hence received fewer sprays. However, it is likely that the comparative vigour of the two fruit fly species also had an effect; the number of Z. cucumis pupae developing in all treatments, including the control, was generally much higher than for B. tryoni. Unpublished data collected for the two fruit fly colonies used in the trials found that egg hatch and total survival to adult in Z. cucumis (94-98\% and 78-87\%, respectively) was higher than B. tryoni (76$87 \%$ and $65-79 \%)$.
Clothianidin (Sumitomo Samurai Systemic Insecticide) was the most effective of the eight insecticides assessed, with both 1- and 3d-aged residues consistently demonstrating efficacy comparable to dimethoate in terms of numbers of pupae developing from treated fruit. Clothianidin was the only insecticide other than dimethoate to significantly affect mortality of adult fruit flies. Two other neonicotinoid insecticides, thiacloprid (Calypso 480 SC Insecticide) and imidacloprid (Confidor 200 SC), also demonstrated efficacy comparable to dimethoate against B. tryoni in terms of reduction in pupal development. However, they were generally much less effective against $Z$. cucumis, and had no effect on adult mortality in either species. Reynolds et al. (2014) found clothianidin to be moderately effective in semifield trials with $B$. tryoni in stonefruit. Neonicotinoids have also proven to be effective against a number of other tephritid species. Rahman and Broughton (2016) found clothianidin and thiacloprid significantly reduced infestation of stonefruit by Mediterranean fruit fly, Ceratitis capitata (Wiedemann), in laboratory trials of 24-h field aged residues. Efficacy was reduced when residues were aged for $7 \mathrm{~d}$. Yee and Alston (2006) found thiacloprid and imidacloprid significantly suppressed infestation by western cherry fruit fly Rhagoletis indifferens Curran in field trials 
in cherry orchards. Reissig (2003) found imidacloprid to be more effective than thiacloprid in laboratory trials with apple maggot, Rhagoletis pomonella (Walsh), but thiacloprid was more effective in orchard trials. The author suggested efficacy was primarily a result of reduced oviposition; neither insecticide resulted in high adult mortality. Hu and Prokopy (1998) demonstrated that whilst imidacloprid was effective against $R$. pomonella via contact (residues applied to glass) and ingestion, it was ineffective when applied to foliage. Similarly, Hu et al. (1998) found imidacloprid to be ineffective for control of $R$. pomonella in apple orchards, suggesting that this was due to rapid absorption by the foliage and degradation by sunlight.

Alpha-cypermethrin (Nufarm Fastac Duo Insecticide) was effective against B. tryoni in capsicums in laboratory and field cage trials, with efficacy of 1-d and 3-d residues comparable to dimethoate. Alpha-cypermethrin was also effective against Z. cucumis in zucchini when tested in the field cage trial, but was less effective in

Table 8. Mean mortality per cage of 20 adult B. tryoni exposed to insecticide residues on capsicum in season two trials; back transformed means (BTM) and predicted means on the logit scale \pm 1 standard error (PM)

\begin{tabular}{|c|c|c|c|c|}
\hline \multirow[t]{2}{*}{ Treatment } & \multicolumn{2}{|c|}{$\begin{array}{c}\text { Lab cage trial, } \\
1 \text { DAT }\end{array}$} & \multicolumn{2}{|c|}{$\begin{array}{c}\text { Lab cage trial, } \\
3 \text { DAT }\end{array}$} \\
\hline & BTM & PM & BTM & PM \\
\hline $\begin{array}{l}\text { Clothianidin } \\
\qquad 40 \mathrm{~g} / 100 \text { liter }\end{array}$ & $6.3 b$ & $-0.79 \pm 0.25$ & $3.2 b$ & $-1.65 \pm 0.29$ \\
\hline $\begin{array}{l}\text { Clothianidin } \\
30 \mathrm{~g} / 100 \text { liter }\end{array}$ & $8.0 \mathrm{~b}$ & $-0.41 \pm 0.23$ & $2.5 b$ & $-1.95 \pm 0.31$ \\
\hline Thiacloprid & $0.3 \mathrm{a}$ & $-4.37 \pm 1.03$ & $0.3 \mathrm{a}$ & $-4.38 \pm 0.86$ \\
\hline Abamectin & 0.0 & $-14.75 \pm \delta$ & 0.0 & $-16.75 \pm \delta$ \\
\hline Spinetoram & $0.3 \mathrm{a}$ & $-4.37 \pm 1.03$ & $0.3 a$ & $-4.38 \pm 0.86$ \\
\hline Dimethoate & $9.0 \mathrm{~b}$ & $-0.20 \pm 0.23$ & $2.7 \mathrm{~b}$ & $-1.84 \pm 0.30$ \\
\hline $\begin{array}{r}\text { Untreated } \\
\text { control }\end{array}$ & 0.0 & $-14.75 \pm \delta$ & $0.3 \mathrm{a}$ & $-4.38 \pm 0.86$ \\
\hline GLMM & & 5.62 & & 4.32 \\
\hline df & & 6,21 & & $6,18.2$ \\
\hline$P$ & & 0.002 & & 0.007 \\
\hline
\end{tabular}

Means with a letter in common are not significantly different (LSD test; $P>0.05)$.

$\delta$ indicates an overinflated standard error. laboratory trials. Reynolds et al. (2014) found that efficacy of alpha-cypermethrin against $B$. tryoni was comparable to fenthion in semifield tests. Various isomers of cypermethrin have demonstrated efficacy against tephritids, for example, cypermethrin reduced infestation and increased yield in a trial to manage Bactrocera spp in cucumber (Sharma et al. 2016); residues of zeta-cypermethrin on cherries effectively reduced oviposition by R. indifferens (Yee and Alston 2012); fresh cypermethrin residues on cucumber prevented oviposition by Dacus ciliatus Loew, the lesser pumpkin fly (Maklakov et al. 2001). Efficacy of the second synthetic pyrethroid assessed, bifenthrin (Talstar 250 EC Insecticide/Miticide) was also comparable with dimethoate in a field cage trial against B. tryoni. However, efficacy in laboratory trials was generally low and this insecticide was ineffective against Z. cucumis. Maklakov et al. (2001) found that fresh bifenthrin residues prevented oviposition by $D$. ciliatus in cucumbers, suggesting that cypermethrin and bifenthrin had a repellent effect on fruit flies. Repellency of pyrethroids has been documented in a variety of insects, including mosquitoes, houseflies, honey bees, Lepidoptera, and mites (Virgona et al. 1983, Rieth and Levin 1988, Hirano 1989, Siegert et al. 2009). A repellent effect could explain the better efficacy achieved for alpha-cypermethrin and bifenthrin in field cage trials, where fruit flies were presented with a choice of treated and untreated fruit, as opposed to laboratory cage trials, where fruit flies were confined in close proximity with treated fruit.

Cyantraniliprole (DuPont Benevia Insecticide) demonstrated efficacy in field cage trials against both fruit fly species, and laboratory cage trials against B. tryoni. It was less effective against $Z$. cucumis. There is relatively little published data on the effect of this new insecticide on tephritid flies. Reynolds et al. (2014) found cyantraniliprole to have little impact on mortality of adult B. tryoni in laboratory tests. Cyantraniliprole significantly reduced adult emergence of B. dorsalis, Z. cucurbitae, and C. capitata, when applied as a soil drench (Stark et al. 2013), and resulted in high adult mortality of B. dorsalis when ingested (Zhang et al. 2015).

Spinetoram (Success Neo Insecticide) was not effective in the field cage trials and had mixed efficacy in the laboratory cage trials. Reynolds et al. (2014) found spinetoram to be moderately effective on mortality of B. tryoni in laboratory tests. Likewise, Yee and Alston (2012) found that this chemical resulted in $81 \%$ mortality of $R$. indifferens females exposed to residues on cherries at

Table 9. Mean number of pupae developing from zucchini exposed to Z. cucumis in season two trials; back-transformed means (BTM) and predicted means on the log scale \pm 1 standard error (PM)

\begin{tabular}{|c|c|c|c|c|c|c|c|}
\hline \multirow{2}{*}{\multicolumn{2}{|c|}{ Treatment }} & \multicolumn{2}{|c|}{ Field cage trial, 1 DAT } & \multicolumn{2}{|c|}{ Lab cage trial, 1 DAT } & \multicolumn{2}{|c|}{ Lab cage trial, 3 DAT } \\
\hline & & BTM & PM & BTM & PM & BTM & PM \\
\hline \multicolumn{2}{|c|}{ Clothianidin $40 \mathrm{~g} / 100$ liter } & 2.8 & $1.02 \pm 4.25$ & $1.7 \mathrm{a}$ & $0.56 \pm 1.75$ & 0.0 & $-13.69 \pm \delta$ \\
\hline \multicolumn{2}{|c|}{ Clothianidin $30 \mathrm{~g} / 100$ liter } & 0.0 & $-15.52 \pm \delta$ & $12.7 \mathrm{a}$ & $2.54 \pm 0.65$ & 1.5 & $0.39 \pm 3.97$ \\
\hline \multicolumn{2}{|c|}{ Thiacloprid } & 376.4 & $5.93 \pm 0.47$ & $90.3 b$ & $4.50 \pm 0.25$ & 189.1 & $5.24 \pm 0.38$ \\
\hline \multicolumn{2}{|c|}{ Abamectin } & 375.3 & $5.93 \pm 0.47$ & $478.3 c$ & $6.17 \pm 0.12$ & 385.9 & $5.96 \pm 0.28$ \\
\hline \multicolumn{2}{|c|}{ Spinetoram } & 361.0 & $5.89 \pm 0.47$ & $151.2 \mathrm{~b}$ & $5.02 \pm 0.20$ & 253.8 & $5.54 \pm 0.34$ \\
\hline \multicolumn{2}{|c|}{ Dimethoate } & 44.8 & $3.80 \pm 1.09$ & $9.0 \mathrm{a}$ & $2.20 \pm 0.77$ & 236.1 & $5.46 \pm 0.35$ \\
\hline \multicolumn{2}{|c|}{ Untreated control } & 423.7 & $6.05 \pm 0.45$ & $797.4 d$ & $6.68 \pm 0.10$ & 243.7 & $5.50 \pm 0.34$ \\
\hline \multirow[t]{3}{*}{ GLMM } & $F$ & \multicolumn{2}{|r|}{0.91} & \multicolumn{2}{|c|}{32.06} & \multicolumn{2}{|r|}{0.87} \\
\hline & df & \multicolumn{2}{|r|}{$6,17.9$} & \multicolumn{2}{|c|}{6,18} & \multicolumn{2}{|r|}{$6,18.1$} \\
\hline & $P$ & \multicolumn{2}{|r|}{0.507} & \multicolumn{2}{|c|}{$<0.001$} & \multicolumn{2}{|r|}{0.538} \\
\hline
\end{tabular}

Means with a letter in common are not significantly different (LSD test; $P>0.05$ ).

$\delta$ indicates an overinflated standard error. 


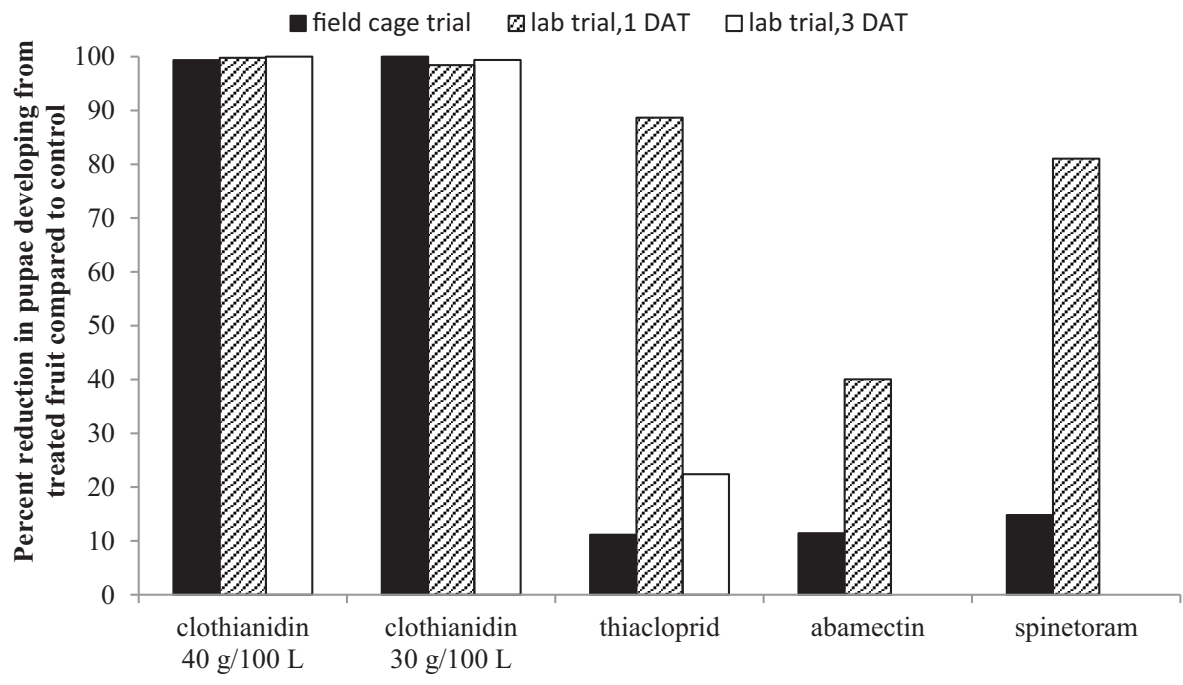

Treatment

Fig. 4. Effect of treatments on reduction in numbers of Z. cucumis pupae developing from treated zucchini compared with control fruit in season two trials.

Table 10. Mean mortality per cage of 20 adult $Z$. cucumis exposed to insecticide residues on zucchini in season two trials; back transformed means (BTM) and predicted means on the logit scale \pm 1 standard error (PM)

\begin{tabular}{|c|c|c|c|c|}
\hline \multirow[t]{2}{*}{ Treatment } & \multicolumn{2}{|c|}{ Lab cage trial, 1 DAT } & \multicolumn{2}{|c|}{ Lab cage trial, 3 DAT } \\
\hline & BTM & PM & BTM & PM \\
\hline $\begin{array}{l}\text { Clothianidin } \\
\qquad 40 \mathrm{~g} / 100 \text { liter }\end{array}$ & $7.5 b$ & $-0.52 \pm 0.25$ & $5.5 b c$ & $-0.97 \pm 0.38$ \\
\hline $\begin{array}{l}\text { Clothianidin } \\
30 \mathrm{~g} / 100 \text { liter }\end{array}$ & $4.5 \mathrm{a}$ & $-1.25 \pm 0.28$ & $2.5 \mathrm{ab}$ & $-1.95 \pm 0.50$ \\
\hline Thiacloprid & 0.0 & $-18.75 \pm \delta$ & $0.3 \mathrm{a}$ & $-4.37 \pm 1.45$ \\
\hline Abamectin & 0.0 & $-18.75 \pm \delta$ & $0.3 \mathrm{a}$ & $-4.37 \pm 1.45$ \\
\hline Spinetoram & 0.0 & $-18.75 \pm \delta$ & $0.3 \mathrm{a}$ & $-4.37 \pm 1.45$ \\
\hline Dimethoate & $11.3 \mathrm{c}$ & $-0.25 \pm 0.25$ & $10.0 \mathrm{c}$ & $0.00 \pm 0.34$ \\
\hline Untreated control & 0.0 & $-18.75 \pm \delta$ & 0.0 & $-15.75 \pm \delta$ \\
\hline GLMM $\quad F$ & & 4.24 & & 9.36 \\
\hline df & & 6,18 & & $6,18.1$ \\
\hline$P$ & & 0.008 & & 0.004 \\
\hline
\end{tabular}

Means with a letter in common are not significantly different (LSD test; $P>0.05)$.

$\delta$ indicates an overinflated standard error.

$24 \mathrm{~h}$, and reduced oviposition compared to controls. Both Reynolds et al. (2014) and Yee and Alston (2012) applied treatments and aged residues under laboratory conditions. Yee et al. (2007) found that aging of spinetoram residues under field conditions resulted in reduced mortality of adult R. pomonella; however, residues remained effective up to $14 \mathrm{~d}$ in terms of preventing oviposition.

Abamectin (Vertimec Miticide/Insecticide) had no effect in field cage trials. One-day residues had a small but significant effect on $B$. tryoni and Z. cucumis in laboratory trials. Kay (2004) found abamectin residues on capsicum resulted in up to $70 \%$ mortality of $B$. tryoni up to $4 \mathrm{~h}$ after dipping, but 24-h residues were less effective. Reynolds et al. (2014) found abamectin residues on stonefruit resulted in high mortality of adult B. tryoni and reduced oviposition. Abamectin is rapidly degraded by exposure to light and air (MacConnell et al. 1989).
In summary, the neonicotinoid clothianidin demonstrated efficacy comparable to dimethoate against both B. tryoni and $Z$. cucumis. Thiacloprid and imidacloprid were also generally effective against B. tryoni. However, there are concerns about effects of neonicotinoids on bees and other pollinator species (Blacquière et al. 2012, Godfray et al. 2014). The synthetic pyrethroid alphacypermethrin was also very effective. However, observations of increased aphid and whitefly activity in alpha-cypermethrin and bifenthrin plots compared with other treatments suggest a disruptive effect on natural enemies. Cyantraniliprole was effective against B. tryoni and is claimed by the manufacturer to be soft on beneficials. Spinetoram, abamectin, and bifenthrin were generally less effective than the other treatments. However, these insecticides are registered in fruiting vegetable crops for control of other pests, and it is likely that their use would have a suppressive effect on fruit flies. It should also be noted that treated fruit were exposed to much higher fruit fly pressure than could be expected in the field, and it is possible that greater efficacy of treatments would be observed in actual use conditions. Large variability between replicates was a problem and may have obscured some treatment effects; incomplete coverage by insecticides may have accounted for some of this variability.

These data represent the first successful trial of the efficacy of insecticides, applied to a vegetable crop as cover sprays, against $B$. tryoni and Z. cucumis. Although Kay (2004) applied insecticides using a similar small plot layout, background fruit fly pressure alone was not sufficient to result in a significant difference amongst treatments. Reynolds et al. (2014) also used a semifield method to compare insecticides for efficacy against B. tryoni; however, although insecticides were applied to fruit in the field, fruit flies were then caged in close proximity to the treated fruit. The field cage method described here allowed for comparison of a number of insecticides under semirealistic conditions. Insecticides were applied to plants and the residues aged under field conditions; fruit flies were exposed to entire plants bearing fruit; and fruit flies were able to choose where to land and oviposit. This allowed for evaluation of effects other than mortality, for example, repellent effects resulting in reduced oviposition. This is significant, as few of the insecticides affected adult mortality in the laboratory cage trials, but the majority 
demonstrated at least a suppressive effect on infestation of fruit in field cage trials.

\section{Acknowledgments}

This study formed part of project VG13041 "New in-field treatment solutions to control fruit fly (1)," funded by Horticulture Innovation Australia using the vegetable industry levy and matched funds from the Australian Government. We thank Kellie Bilney, Ania Ganowicz, Chloe Jacobs, Mary Firrell, and John Duff for technical assistance, Thelma Peek for providing fruit flies, Gatton Research Facility staff for maintaining the trial site, and Geoff Cornwell (DuPont Crop Protection Australia) and Doug Paton (Sumitomo Chemical Australia Pty Ltd) for supplying insecticide samples. Earlier versions for this manuscript were improved by comments from Pauline Wyatt, Peter Leach and two anonymous reviewers.

\section{References Cited}

Abbott, W. S. 1925. A method of computing the effectiveness of an insecticide. J. Econ. Entomol. 18: 265-267.

(APVMA) Australian Pesticides and Veterinary Medicines Authority. 2011. Use of the insecticide dimethoate suspended on many food crops. (http:// apvma.gov.au/node/11771) (accessed 30 March 2017).

(APVMA) Australian Pesticides and Veterinary Medicines Authority. 2015. Fenthion chemical review. (http://apvma.gov.au/node/12541) (accessed 30 March 2017).

(APVMA) Australian Pesticides and Veterinary Medicines Authority. 2016. Dimethoate chemical review. (http://apvma.gov.au/node/12496) (accessed 30 March 2017).

(APVMA) Australian Pesticides and Veterinary Medicines Authority. 2017. Dimethoate chemical review. (http://apvma.gov.au/dimethoate), accessed 30 March 2017.

Atuahene, S.K.N., and G.H.S. Hooper. 1971. Insecticide susceptibility of, and metabolism of DDT by Dacus tryoni (Froggatt) and Dacus cucumis French (Diptera: Tephritidae). J. Aust. Entomol. Soc. 11: 135-142.

Balagawi, S., K. Jackson, and A. R. Clarke. 2014. Resting sites, edge effects and dispersion of a polyphagous Bactrocera fruit fly within crops of different architecture. J. Appl. Entomol. 138: 510-518.

Blacquière, T., G. Smagghe, C.A.M. van Gestel, and V. Mommaerts. 2012. Neonicotinoids in bees: A review on concentrations, side-effects and risk assessment. Ecotoxicology 21: 973-992.

Clarke, A. R., K. S. Powell, C. W. Weldon, and P. W. Taylor. 2011. The ecology of Bactrocera tryoni (Froggatt) (Diptera: Tephritidae): What do we know to assist pest management? An. Appl. Biol. 158: 26-55.

Dominiak, B. C., B. Wiseman, C. Anderson, B. Walsh, M. McMahon, and R. Duthie. 2015. Definition of and management strategies for areas of low pest prevalence for Queensland fruit fly Bactrocera tryoni Froggatt. Crop Prot. 72: 41-46.

Drew, R.A.I., G.H.S. Hooper, and M. A. Bateman. 1982. Economic fruit flies of the South Pacific region, 2nd ed. Queensland Department of Primary Industries, Brisbane, Australia.

Godfray, H.C.J., T. Blacquière, L. M. Field, R. S. Hails, G. Petrokofsky, S. G. Potts, N. E. Raine, A. J. Vanbergen, and A. R. McLean. 2014. A restatement of the natural science evidence base concerning neonicotinoid insecticides and insect pollinators. Proc. R. Soc. B. 281: 20140558.

Gu, H. 2010. Alternative fruit fly treatment for interstate market access for strawberries. Horticulture Australia Project Number BS06002 Final Report, Horticulture Australia Ltd, Sydney, Australia.

Hancock, D. L., E. L. Hamacek, A. C. Lloyd, and M. M. Elson-Harris. 2000. The distribution and host plants of fruit flies (Diptera: Tephritidae) in Australia. Queensland Department of Primary Industries Information Series QI99067, Brisbane, Australia.

Heather, N. W., and R. J. Corcoran. 1985. Dacus tryoni, pp. 41-48. In P. Singh and R. F. Moore (eds.), Handbook of insect rearing, vol 2. Elsevier, Amsterdam, The Netherlands.

Hirano, M. 1989. Characteristics of pyrethroids for insect pest control in agriculture. Pestic. Sci. 27: 353-360.
Hu, X. P., A. Kaknes, and R. Prokopy. 1998. Can apple maggot fly control benefit from sprays of Provado aimed at killing leafminers and leafhoppers? Fruit Notes 63: 4-6.

Hu, X. P., and R. J. Prokopy. 1998. Lethal and sublethal effects of imidacloprid on apple maggot fly, Rhagoletis pomonella Walsh (Dipt., Tephtritidae). J. Appl. Entomol. 122: 37-42.

Kay, I. 2004. Heliothis and fruit fly integrated pest management strategies for tomato, vegetable and melon crops. Horticulture Australia Project Number VX99035 Final Report, Horticulture Australia Ltd, Sydney, Australia.

Khursheed, S., and D. Raj. 2012. Bio-efficacy of certain insecticides and biopesticides against melon fruit flies, Bactrocera spp. Pest Manag. Hort. Ecosyst. 18: 143-148.

MacConnell, J. G., R. J. Demchak, F. A. Preiser, and R. A. Dybas. 1989. Relative stability, toxicity, and penetrability of abamectin and its 8,9-oxide. J. Agric. Food Chem. 37: 1498-1501.

Macfadyen, S., J. E. Banks, J. D. Stark, and A. P. Davies. 2014. Using semifield studies to examine the effects of pesticides on mobile terrestrial invertebrates. Ann. Rev. Entomol. 59: 383-404.

Maklakov, A., I. Ishaaya, A. Freidberg, A. Yawetz, A. R. Horowitz, and I. Yarom. 2001. Toxicological studies of organophosphate and pyrethroid insecticides for controlling the fruit fly Dacus ciliatus (Diptera: Tephritidae). J. Econ. Entomol. 94: 1059-1066.

McQuate, G. T. 2011. Assessment of attractiveness of cassava as a roosting plant for the melon fly, Bactrocera cucurbitae, and the oriental fruit fly, B. dorsalis. J. Insect Sci. 11: 30.

Mosleh, Y. Y., S.F.M. Moussa, and L.H.Y. Mohamed. 2011. Comparative toxicity of certain pesticides to peach fruit fly, Bactrocera zonata Saunders (Diptera: Tephritidae) under laboratory conditions. Plant Prot. Sci. 47: 115-120.

Nishida, T., and H. A. Bess. 1957. Studies on the ecology and control of the melon fly Dacus (Strumeta) cucurbitae Coquillett (Diptera: Tephritidae). Tech. Bull. Hawaii. Agric. Exp. Stn. 34: 44. pp.

Oke, O. A. 2008. Effectiveness of two insecticides to control melon fruit fly (Bactrocera cucurbitae Coq.) in cucumber (Cucumis sativus L.) crop at Anse Boileau Seychelles. Eur. J. Sci. Res. 22: 84-86.

Oke, O. A., and S. G. Sinon. 2013. Effectiveness of three insecticides to control Bactrocera cucurbitae (Diptera: Tephritidae) on the cucumber crop at Praslin, Seychelles. Fla. Entomol. 96: 120-123.

Prokopy, R. J., N. W. Miller, J. C. Piñero, J. D. Barry, L. C. Tran, L. Oride, and R. I. Vargas. 2003. Effectiveness of GF-120 fruit fly bait spray applied to border area plants for control of melon flies (Diptera: Tephritidae). J. Econ. Entomol. 96: 1485-1493.

Rahman, T., and S. Broughton. 2016. Evaluation of thiacloprid and clothianidin (neonicotinoids) as alternative to fenthion (organophosphate) for control of Mediterranean fruit fly (Diptera: Tephritidae) in deciduous fruit orchards. Crop Prot. 90: 170-176.

Reissig, W. H. 2003. Field and laboratory tests of new insecticides against the apple maggot, Rhagoletis pomonella (Walsh) (Diptera: Tephritidae). J. Econ. Entomol. 96: 1463-1472.

Reynolds, O. L., A. Jessup, T. Osborne, K. Bodnaruk, J. Archer, K. Eamens, and I. Barchia. 2014. Efficacy of potential controls for Queensland fruit fly management in summerfruit. Horticulture Australia Project Number SF12012 Final Report, Horticulture Australia Ltd, Sydney, Australia.

Rieth, J. P., and M. D. Levin. 1988. The repellent effect of two pyrethroid insecticides on the honey bee. Physiol. Entomol. 13: 213-218.

Sharma, S. K., Unam, and R. Kumar. 2016. Management of fruit fly (Bactrocera spp.) in cucumber (Cucumis sativus Linn.) grown organically. J. Biopest. 9: 73-79.

Siegert, P. Y., E. Walker, and J. R. Miller. 2009. Differential responses of Anopheles gambiae (Diptera: Culicidae) modulate mortality caused by pyrethroid-treated bednets. J. Econ. Entomol. 102: 2061-2071.

Stark, J. D., R. I. Vargas, S. L. Souder, A. J. Fox, T. R. Smith, and B. Mackey. 2013. A comparison of the bioinsecticide, spinosad, the semi-synthetic insecticide, spinetoram and synthetic insecticides as soil drenches for control of tephritid fruit flies. Biopestic. Int. 9: 120-126.

Steiner, L. F., and F. G. Hinman. 1952. Field tests of insecticides for control of oriental fruit fly. J. Econ. Entomol. 45: 388-395. 
Subramaniam, S. 2013. Alternative fruit fly control for market access and to enhance integrated pest management in eggplant. Horticulture Australia Project Number VG09023 Final Report, Horticulture Australia Ltd, Sydney, Australia.

Swaine, G., R. J. Corcoran, and M. Davey. 1978. Commodity treatment against infestations of the cucumber fly, Dacus (Austrodacus) cucumis French, in cucumbers. Qld. J. Agric. Anim. Sci. 35: 5-9.

Vargas, R. I., J. C. Piñero, and L. Leblanc. 2015. An overview of pest species of Bactrocera fruit flies (Diptera: Tephritidae) and the integration of biopesticides with other biological approaches for their management with a focus on the Pacific region. Insects 6: 297-318.

Virgona, C. T., G. Holan, and E. Shipp. 1983. Repellency of insecticides to resistant strains of housefly. Entomol. Exp. Appl. 34: 287-290.

VSN International 2013. GenStat for Windows, version 16th ed. VSN International, Hemel Hempstead, United Kingdom.

Wang, J.-J., D. Wei, W. Dou, F. Hu, W.-F. Liu, and J.-J. Wang. 2013. Toxicities and synergistic effects of several insecticides against the oriental fruit fly (Diptera: Tephritidae). J. Econ. Entomol. 106: 970-978.
Wise, J. C., R. Vanderpoppen, and C. Vandervoort. 2009. Curative activity of insecticides on Rhagoletis pomonella (Diptera: Tephritidae) in apples. J. Econ. Entomol. 102: 1884-1890.

Yee, W. L. 2008. Effects of several newer insecticides and kaolin on oviposition and adult mortality in western cherry fruit fly (Diptera: Tephritidae). J. Entomol. Sci. 43: 177-190.

Yee, W. L., and D. G. Alston. 2006. Effects of spinosad, spinosad bait, and chloronicotinyl insecticides on mortality and control of adult and larval western cherry fruit fly (Diptera: Tephritidae). J. Econ. Entomol. 99: 1722-1732.

Yee, W. L., and D. G. Alston. 2012. Behavioral responses, rate of mortality, and oviposition of western cherry fruit fly exposed to malathion, zetacypermethrin, and spinetoram. J. Pestic. Sci. 85: 141-151.

Yee, W. L., O. Jack, and M. J. Nash. 2007. Mortality of Rhagoletis pomonella (Diptera: Tephritidae) exposed to field-aged spinetoram, GF-120, and azinphos-methyl in Washington State. Fla. Entomol. 90: 335-342.

Zhang, R., E. B. Jang, S. He, and J. Chen. 2015. Lethal and sublethal effects of cyantraniliprole on Bactrocera dorsalis (Hendel) (Diptera: Tephritidae). Pest Manag. Sci. 71: 250-256. 